\title{
Raymond Aron y la teoría de las relaciones internacionales
}

\author{
Raymond Aron and the theory \\ of international relations
}

Pablo A. Anzaldi*

Resumen

En el presente trabajo se examina la obra International Relations de Raymond Aron como un proceso de desarrollo a lo largo de tres decenios, en que política, guerra y tecnología se analizan y reinterpretan de tres diferentes maneras.

La primera depende del pensamiento de Spengler, mientras que la segunda y la tercera se basan en una interpretación detenida y original de Clausewitz.

Palabras Clave: guerra, política. Aron, Clausewitz

\section{Abstract}

The paper examines Raymond Aron's International Relations as a process of development along three decades, where politics, war and technology are analyzed and reinterpreted in three different manners.

Director, línea de Política Internacional, Instituto de Política Internacional, Polemología y Estrategia Contemporánea, Universidad de la Plata (pabloanzaldi5@hotmail. com).

Basado en la tesis de Magíster en Ciencia Política de la Pontificia Universidad Católica de Chile.

Recibido el 10 de diciembre de 2007; aceptado el 3 de enero de 2008. 
The first depends on Spengler`s thought, while the second and third are based in a deep and original interpretation of Clausewitz.

KEY wORDs: war, politics, Aron, Clausewitz 
Pablo A. Anzaldi • Raymond Aron y la teoría de las relaciones internacionales

La política, la paz y la guerra fueron el sino de los años de ruido y furor en que vivió Raymond Aron (1905-1983). La Primera Guerra Mundial, la revolución bolchevique, el fascismo europeo, el ascenso de Hitler, la escalada hacia una nueva guerra, la ocupación alemana de Francia, el gobierno de Vichy, la Segunda Guerra Mundial, los campos de exterminio, el gaullismo, las bombas atómicas, la bipolaridad, la descolonización, Argelia, las carreras de armamentos, las guerras revolucionarias, mayo del 68, las modas intelectuales, fueron algunos de los hitos atravesados por el pensamiento y el análisis de Aron. La singular personalidad intelectual se desplegó en abanico hacia las más variadas disciplinas teóricas. Aron fue filósofo, sociólogo, politólogo, teórico de las relaciones internacionales, estratega, historiador, periodista político, crítico de ideas, teórico liberal, pensador de la cultura occidental: la cantidad de materias abordadas nos proporciona una idea de su especial talento. A pesar de su extraordinaria trayectoria académica, el agudo sentido de lo político que poseía lo mantenía -si no físicamente, al menos en lo espiritual- a cierta distancia del mundo universitario. Por ello, en una oportunidad dijo que «a los que han pasado toda su vida en una universidad, primero como estudiantes y luego como profesores, les falta algo. El mundo universitario es demasiado suave. En él se conoce insuficientemente la maldad, la dureza de la existencia humana» (Aron, 1985: 25).El pensamiento aroniano -como el de todo pensador serio, sustraído a los alardes del público- desborda con creces los avatares de su vida. Si en su biografía hay algo que explique su posición y orientación, es de hacer notar que fue judío, francés y liberal en el siglo del holocausto del pueblo elegido, cuando Francia fue arrasada y las tiranías se enseñoreaban en Europa. En Aron, la posición política y el ejercicio de la actividad teórica se dan la mano. El liberalismo de Aron se basa en la oposición a las tiranías del siglo XX, más que en doctrinarismos. Su enemistad con la tiranía soviética se expresa en una investigación sobre el marxismo que atraviesa todos o casi todos sus libros, articulándose con la meditación sobre el destino histórico de Europa y Occidente, con los viejos y nuevos problemas de la siempre renovada vida política.Si la tendencia a refugiarse en una hipótesis teórica hasta el punto de hacer irreconocible la realidad política es un peligro que trató de evitar, no es porque restase importancia a las ideas sino más bien lo contrario: Aron pensaba que la realidad política funcionaba en consonancia con las ideas. Nunca soltó amarras con la historia política, en tanto le proporcionaba los materiales de la realidad; ni circunscribió su meditación a una única tesis fuerte (en rigor una hipótesis), para así captar las ideas que operaban en la realidad. El encuentro de esas ideas posibilitaba que su propio pensamiento fuese una dimensión misma de la realidad, y no 
en menor medida en su función de docente y editorialista. Continuando una antigua tradición occidental, para la que ya apenas quedan adeptos, su saber emanó siempre de la búsqueda de la verdad y no se subordinó jamás a su periodismo.

Aron es un clásico. En el doble sentido de la palabra, esto es, en tanto su pensamiento no ha envejecido en lo fundamental, y en ese peculiar estilo de reunir lo efectivo, lo noble y lo posible en un mismo despliegue intelectual. Su identidad de pertenencia a un universo de pensamiento clásico se vislumbra en el encuentro de la política y la filosofía en la elaboración teórica, en el carácter crítico y polémico que adquieren sus escritos frente a las novedades - acaso modas- intelectuales. La dimensión filosófica de su pensamiento articula las categorías teóricas con los datos de la realidad, ejerciendo la crítica al dogmatismo -en cualquiera de sus manifestaciones-, y desplegando una conciencia concreta de la vida política. También puede hallarse como constante en muchos de sus textos la triple articulación de los niveles analítico-conceptuales, histórico-explicativos y orientador de la acción, porque Aron fue un observador comprometido en el gran estilo intelectual francés del siglo XIX.

Realmente Aron pertenecía a una rara especie de hombres pensadores para los cuales la vida gira en torno a la política y esta, en lo fundamental, ha sido teorizada en el pasado:
D.W.- Usted abandonó Alemania en 1933. A su regreso a Francia, ¿en qué aspecto estaba más cambiado?

R.A.- Tomé conciencia del mundo. En otras palabras, hice mi educación políticamente. Y no sentimentalmente. Al llegar a Alemania en la primavera de 1930 era un novato. En 1933 volví a Francia siendo adulto. Tomé conciencia de lo que es la política en lo que de horrible puede tener. Pero no fue Alemania como tal quien me cambió. Fue Hitler en una Alemania que se había hitlerizado. Eso es todo. No es mucho. Podría haberlo aprendido leyendo libros, pero lo aprendí en la realidad.

D.W.- ¿Cree realmente que leyendo libros...?

R.A.- Sí, Aristóteles y Maquiavelo. Habría bastado probablemente con comprenderlos bien (Aron, 1983: 39).

La alusión a Aristóteles y a Maquiavelo no es casual, ni responde al gusto del público francés de entonces, sumergido en la última moda intelectual, el posestructuralismo. Aristóteles es el padre de la ciencia política, cuyo carácter arquitectónico se adecua a la naturaleza humana, esencialmente política. Maquiavelo es el padre de la ciencia política moderna, el profeta desarmado de una nueva era en la que la naturaleza carece de carácter teleológico y se desatan las pasiones humanas, apenas encauzadas por una creciente ordenación técnica. Aristóteles vio en la tiranía una desviación de los regímenes políticos; Maquiavelo, al suprimir la distinción entre lo bueno y lo malo, al borrar la diferencia entre el príncipe y el tirano, trasegó al príncipe caracteres que los antiguos veían en el tirano y 
Pablo A. Anzaldi • Raymond Aron y la teoría de las relaciones internacionales

mezcló el vicio y la virtud como partes de la verdad efectiva de la cosa.

\section{II}

El encuentro de Raymond Aron con la disciplina de las relaciones internacionales constituye uno de los tantos planos en los que desenvuelve su pensamiento. Autores como Stanley Hoffmann( 1991), Celestino del Arenal (1994), James Dougherty y Robert Pfaltzgraff (1993) consideran a Paz y Guerra entre las Naciones como la contribución excluyente de Aron a la disciplina. Sin embargo, la caracterización de Aron como un «espectador comprometido» (Aron, 1983) posibilita una interpretación más amplia del corpus teórico perteneciente a las relaciones internacionales.

Así y todo, el carácter multifacético de la obra de Aron ligada a las relaciones internacionales constituye un serio desafío para el intérprete. En la medida en que el pensamiento aroniano se despliega a lo largo de una obra tan vasta, en la que la cantidad de autores y perspectivas trabajadas es tan amplia, condiciona al intérprete a una tarea ardua. La indagación teórica es necesariamente provisional e inagotable, ya que se cruzan los antiguos y los modernos, los estadistas y los procesos políticos, los problemas filosóficos de la historia y los problemas de la historia de la filosofía, remitiendo todo -como clave de bóveda- a unas relaciones internacionales cuyo centro de convergencia es la política mundial.
A pesar de estas dificultades, la unidad de problemática del pensamiento aroniano en relaciones internacionales puede hallarse en la meditación sobre la política, la guerra y la paz. Como no era un utopista ni un esteta -ni de la paz ni de la guerra- el abordaje de la cuestión bélica a lo largo de toda su trayectoria intelectual se desprende naturalmente de lo histórico-político.

En respuesta a un comentario acerca de su insistencia en la cuestión de la guerra en sus libros, Aron replica:

Pero dígame, ¿acaso no sabe lo que hemos vivido en el siglo XX? ¿Acaso no sabe que uno de los grandes acontecimientos de esta historia fue la Primera Guerra Mundial, y otro acontecimiento aún más grande la Segunda? De esa segunda guerra surgió el poderío de la Unión Soviética...(...)... podría decirse simplemente que me ha fascinado el carácter misterioso e inteligible a la vez de las grandes guerras que son parte de lo que yo llamo en un artículo «history as usual», es decir, la historia como de costumbre. Esa historia son naciones, guerras, héroes, víctimas (1983:194-5).

Los intereses científicos y políticos en Aron están indisolublemente ligados. Un debate característico como el del realismo y el idealismo no se le aplica fácilmente. La misma amplitud de su obra convierte a la tarea clasificatoria en una suerte de lecho de Procusto. El estilo aroniano es ajeno a las posturas afectadas del realismo clásico, tales como el reduccionismo a los intereses nacionales y la política de poder. Para 
Aron la política no solo implica cálculo sino también pasiones, ideales, fines, odios. Por ello no es exponente típico de ninguna escuela.

A menudo sus escritos están atravesados por unidades de análisis diversas e incluso contradictorias. Cualquier lector atento de Paz y Guerra entre las Naciones encontrará el empleo de categorías conductistas como el diplomático y el soldado, y otras sistémicas, como la distinción entre sistemas homogéneos y heterogéneos.

Las sucesivas aproximaciones intelectuales a la realidad política, que opera como elemento del pensar aroniano, están jalonadas por distintos momentos teóricos. No son ajenos a estos los virajes y reorientaciones, aunque Aron no haya sido especialmente enfáticoquizás por un proverbial sentido de la modestia- en señalar esos virajes y rectificaciones.

En gran medida, el desarrollo teórico de Aron en relaciones internacionales es una descripción de la circunstancia histórica, en sentido amplio, a partir de una creciente interpretación del pensamiento de Clausewitz como clave fundamental de la teoría político- estratégica.

Nuestra estrategia investigativa interpreta al pensamiento aroniano como proceso de desarrollo en el que pueden establecerse tres fases o momentos, determinados por tres respectivos modos de conceptuar la relación entre las variables política, guerra y técnica ${ }^{1}$.

1 La cuestión acerca de la autoconciencia de Aron sobre la trayectoria de su propio
Las distintas presentaciones de su trayectoria intelectual aparecen como un progresivo ahondamiento en el «círculo virtuoso» entre la teoría clausewitziana y la realidad política del mundo.

El primer momento del pensamiento aroniano corresponde a un género «filosófico-periodístico» y está determinado y fundamentado en la tesis de la primacía de la técnica sobre la guerra y de esta sobre la política.

El segundo momento corresponde a una concepción de transición de la política y la guerra caracterizada por un modo ecléctico de tratamiento de una serie de conceptos de diversa procedencia.

El tercer momento despliega la tesis de la primacía de la política sobre la guerra y la técnica y se fundamenta en una interpretación específicamente política del pensamiento de Clausewitz.

La unidad esencial de todos los momentos formales así como de las fases de reorientación y profundización están

pensamiento pertenece a la biografía, por lo tanto está fuera de nuestra investigación. Conviene destacar algunos indicadores como la alusión al género "filosófico-periodístico» (Aron, 1983:279), y cuando manifiesta "insatisfacción» ante el tratamiento de Clausewitz en $\mathrm{Paz} y$ Guerra entre las Naciones (Aron, 1988:4). De todos modos, la hermenéutica pertenece al lector más que al autor.

Por otro lado, la ubicación temporal de las fases del pensamiento aroniano es aproximada y ha sido trazada en función de la aparición de los trabajos teóricos. El movimiento del pensamiento determina la relación con el tiempo usual. Lejos estamos, pues, de sostener lo inverso. 
posibilitadas por la distinción amigoenemigo como momento esencial de la realidad política. El despliegue del pensamiento aroniano es un movimiento de profundización en la comprensión de este aspecto, al cual remite en tanto esencia.

\section{III}

En Les guerres en chaine ${ }^{2}$, publicado en 1951, la guerra y la política aparecen como fenómenos independientes y en tensión. La guerra es concebida jerárquicamente superior en el orden de determinación del proceso histórico:

Las guerras son esencialmente impronosticables. Pero las guerras del siglo XX lo son mucho más que las del pasado. Las mismas situaciones que preparan una guerra moderna se destruyen al nacer. Es la batalla en y por sí, y no el origen del conflicto o del tratado de paz, lo que constituye el hecho importante y produce las consecuencias de mayor alcance (Aron, 1973: 14).

El militarismo teórico de Aron encuentra aquí su más alta manifestación. No solo las «situaciones que preparan una guerra moderna se destruyen al nacer", de modo tal que la guerra invierte la relación de efecto de determinadas condiciones cobrando independencia entitativa, sino también, en el proceso mismo de la guerra, es el momento de

2 Todas las citas corresponden a la edición en castellano (1973) de Un siglo de guerra total. Ver en la bibliografía. la batalla el que se manifiesta emancipado y decisivo. La batalla «en y por sí» es el punto de expresión más alto del militarismo teórico aroniano ${ }^{3}$.

¿Cuál es la gravitación de la política ante una batalla que "constituye el hecho importante» que "produce las consecuencias de mayor alcance? ¿Cuáles son los supuestos del pensamiento aroniano que configuran una idea de la batalla como determinación principal?

La tesis sobre la que se apoya la independencia y superioridad de la batalla sobre la política es la primacía de la técnica. El mismo Aron escribirá sobre esas páginas años después que «el tema de la tecnificación del mundo pertenece tanto a Saint- Simon y Marx como a Spengler y Heidegger. Lo que se discutía inmediatamente después de la guerra y se sigue discutiendo todavía hoy es el porvenir que trae consigo la revolución técnica, el destino que reserva a Occidente» (1985:288).

El militarismo es eminentemente teórico, en el sentido en que una teoría articula y relaciona jerárquicamente conceptos que dan cuenta de una realidad. No hay en Aron, pues, romanticismo de la guerra alguno. Cuando Aron afirma que «la 'sorpresa técnica' está entre las principales causas de la extensión geográfica de la guerra y el crecimiento de las pasiones en tiempo de guerra» (1973:18), la tensión entre

3 Subrayamos que el militarismo de Aron es de orden teórico, no doctrinario ni ideológico. 
el instrumento militar y el diplomático parece haberse decidido en función del primero: la técnica se presenta en el esplendor de su poderío derrumbando todos los controles y poderes humanos.

Es una idea de la técnica de raíz spengleriana, no marxista. Para Marx, la técnica es condición de desarrollo de las fuerzas productivas mediante la división del trabajo. Es lo que Heidegger denomina concepción antropológica de la técnica: la técnica es un instrumento en las manos del proletariado encargado del trabajo físico, determinado por el trabajo intelectual, creador. No hay posibilidad de que el dispositivo técnico adquiera independencia del proceso de producción. La división técnica del trabajo, el desarrollo creciente de la especialización en el proceso de producción, crea las bases de la futura sociedad comunista. En cambio, para Spengler, a través de la máquina la técnica creada se subleva contra el creador, alcanzando un plano determinante y decisivo(Spengler, 1993:584).

Spengler analiza la historia de la técnica desde la prolongación de la mano hasta la aparición de la máquina, que determina la tragedia del hombre en el dominio de lo fáustico. La afirmación aroniana en el sentido de que «la fuerza motriz de la evolución de aquel tiempo era técnica» recapitula la línea de pensamiento spengleriana, puesto que articula el reconocimiento de la gravitación de la técnica y su peligro.

El registro discursivo de Spengler es filosófico-histórico y cultural. El de
Aron es periodístico-filosófico (Aron, 1985: 279).

La sustitución de la diplomacia por la guerra sobredeterminada por la técnica supone la irreductibilidad entre la técnica y la diplomacia -a diferencia de la concepción clausewitziana- e implica el extravío de la racionalidad de la acción humana. El ámbito de los medios se mueve por sí mismo, independientemente de los orígenes y de los fines. La guerra es una realidad políticamente inmanejable. La hermenéutica del pasado histórico es decisivamente determinada por la violencia desencadenada del presente.

En cualquier caso, esta determinó a aquella. La «sorpresa técnica» destrozó los límites diplomáticos y las consideraciones políticas: los fines se tornaron ilimitados, la guerra impuso su lógica destructiva a la política, que dejó paso a una guerra a muerte. La pérdida de influencia de los diplomáticos y la ruptura de la tradición diplomática de las naciones europeas resultaron de la capacidad destructiva de la guerra.

La separación entre los conceptos de política y guerra refuerza el militarismo teórico de Aron. La guerra aparece como una realidad independiente, determinante. La política se le subordina. Si la guerra alcanza su punto máximo de despliegue, constituyéndose en «guerra total», la política deviene impotente.

El dinamismo de la guerra total impone sus propios objetivos, políticamente dislocados. La guerra se transforma en guerra a ultranza. De principio a fin, 
la dinámica de la guerra total arrastra a los actores hacia la destrucción. La exigencia de rendición incondicional a Alemania aparece como un epifenómeno de la guerra total y no como una política, seleccionada o no, entre otras posibles (Aron, 1973). La guerra total no deja margen a la acción política, más allá de una función instrumental y subordinada. En esta primera fase, el pensamiento aroniano se despliega en la descripción de una sucesión abigarrada de fenómenos empíricos, a los que ensaya encuadrar desde el postulado de la primacía de la técnica. La relación entre los fenómenos y el postulado dista de estar construida como totalidad de determinaciones. Aron aún no ha construido una teoría de las relaciones internacionales.

La primacía de la técnica es la tesis modeladora porque la guerra se eleva sobre sí misma y se apoya en la técnica como fundamento último. La técnica es lo infundado, lo real por sí mismo, el arco último que corona el conjunto.

Por otro lado, la primacía de la técnica y de la guerra sobre la diplomacia, y la distinción subyacente y supuesta entre esta y la política constituyen una fase pre-clausewitziana, en relación con la evolución posterior de su pensamiento, lo que demostraremos en los próximos párrafos.

\section{IV}

La publicación de Paz y Guerra entre las Naciones en 1962 marca un hito en la producción teórica aroniana y en la historia de la disciplina de las relaciones internacionales. Las fuentes teóricas del voluminoso texto adquieren una dimensión en cierto sentido obnubilante, ya que implican a la más amplia tradición filosófico-política. El esfuerzo aroniano de ordenación de los materiales teóricos e históricos es motivado por la idea regulativa de construir un libro que adquiera vigencia de clásico.

Aron recupera la idea según la cual las grandes crisis son aclaradas en los grandes libros, como La República de Platón, La Política de Aristóteles, El Leviathan de Hobbes y el Tratado Político de Spinoza; así como en los libros de Locke, Montesquieu y Rousseau, que escribieron en el período comprendido entre la revolución inglesa y la francesa (1963: 19).

Así, la crisis de la ciudad antigua, de la cristiandad europea y de las revoluciones inglesa y francesa contó con grandes intérpretes, cuyos nombres forman parte de la historia del pensamiento occidental. La evocación de las grandes crisis del pasado y sus filósofos muestra la autoconciencia aroniana de la relación entre la bipolaridad soviético-norteamericana y su propio pensamiento.

Para Aron la crisis de la época aún no ha encontrado su gran libro.

La construcción del objeto de las relaciones internacionales como relaciones entre "unidades políticas» alcanza el máximo nivel de abstracción en relación a las modalidades concretas que asumen las unidades políticas en el curso de la historia. 
La reformulación de las «relaciones internacionales» como «relaciones interestatales» y la identificación de éstas con las «relaciones» entre las «unidades» en tanto "centros autónomos de decisión», indica el punto máximo del esfuerzo aroniano por desprender a las relaciones internacionales de la dependencia del momento histórico en que despliega la investigación( 1963: 37).

El problema de los límites del objeto de las relaciones internacionales determina una serie de intentos por descubrir una unidad de análisis funcional a una teoría de las relaciones internacionales que justifique la autonomía de la disciplina respecto del conocimiento político en general. Sin embargo, la selección de la unidad de análisis denominada «unidad política» le permite solo formalmente sustraer su pensamiento de la dependencia respecto del período histórico político moderno. Aron afirma que «en ausencia de naciones conscientes de ellas mismas y de Estados jurídicamente organizados, la política interior y la política exterior tienden a confundirse, ya que aquélla no es esencialmente pacífica y esta última tampoco es radicalmente belicosa».

Las limitaciones del contenido estatalista de las relaciones internacionales, así como los intentos de trascender la era del Estado nación, emergen en la meditación teórica aroniana. No solo es ampliamente discutible la ecuación que identifica a la política interior con la paz y a la política internacional con la guerra- lo que Aron designa como "oposición frecuente en la filosofía política»- sino que, en rigor, no puede afirmarse taxativamente nada de ello, ya que ambas políticas- siguiendo el razonamiento- «tienden a confundirse».

El límite de una teoría de las relaciones internacionales apoyada en una tesis de la estatalidad como soporte de lo político encuentra aquí su máxima expresión: hay situaciones ambiguas en las que la política interior y la política exterior no son distinguibles. En consecuencia, la distinción entre la política interior y la política internacional como fuentes de la paz y de la guerra, respectivamente, encuentra una seria objeción.

\section{V}

El tipo ideal weberiano es una representación e imagen estilizada de un aspecto de la realidad social. No es un concepto, en tanto no levanta el contenido acabado de lo real, ni da cuenta de la adecuación intelectual a la cosa.

El diplomático y el soldado son expresiones particulares de un tipo ideal, correspondiente a las relaciones internacionales.

En la medida en que estos tipos ideales son portadores de una conducta específica (el diplomático, el discurso oral y escrito; el soldado, el combate) su carácter de símbolo y representación de la unidad política en cuyo nombre actúan se orienta hacia una interpretación conductista. En efecto, en Paz y Guerra, tanto la paz como la guerra de 
la conducta de dos sujetos portadores, ya que «el embajador y el soldado viven y simbolizan las relaciones internacionales que, en tanto interestatales, nos llevan a la diplomacia y a la guerra». Los Estados se relacionan a través de diplomáticos y de soldados.

La primera parte de Paz y Guerra denominada Teoría, conceptos y sistemas, constituye un conjunto en el que se integran conceptos pertenecientes a distintos registros teóricos, entre los que se destacan la idea del estado de naturaleza, una primera interpretación del pensamiento de Clausewitz, la tesis weberiana de la política como profesión, una teoría política dependiente de una teoría del Estado, figuras inspiradas desde el conductismo y el recurso a la teoría de sistemas. La magnitud del esfuerzo aroniano por construir una síntesis teórica con elementos de tan diversas procedencias -sometidos uno a uno a examen crítico- constituye una novedad en la disciplina de las relaciones internacionales.

La fuerza del entendimiento aroniano lleva al empleo de un instrumental teórico cuya articulación en la configuración de una teoría de conjunto es necesariamente problemática. En este punto, el sino del pensamiento aroniano se encuentra con Clausewitz, como teórico fundacional de una teoría político militar que puede constituirse en el núcleo de la teoría de las relaciones internacionales. Pero Clausewitz es un autor que exige una especial interpretación, ya que su teoría ha sido recurrentemente deformada por los intérpretes.
La profundización de la tarea crítica de rescate del pensamiento de Clausewitz incia su marcha en Paz y Guerra entre las Naciones. Clausewitz proporciona la base sobre la que Aron edifica la teoría (sobre Clausewitz trata el capítulo primero de la Primera Parte). Por lo tanto, el tratamiento de esta cuestión configura una clave hermenéutica determinante para la comprensión de Paz y Guerra.

En el pensamiento de Clausewitz la distinción entre guerra absoluta y guerra real es el punto de partida de su rehabilitación en la historia de la teoría política occidental. No se trata de una reposición de anticuario, a partir de las excelencias pasadas, relativas a circunstancias caídas en el olvido. Por el contrario, Aron recupera a Clausewitz como creador de los conceptos fundamentales de la teoría de las relaciones internacionales.

La guerra absoluta es el concepto abstracto de guerra y como tal pone en juego el ascenso a los extremos y la aniquilación de uno de los contendientes. La guerra absoluta no es ni una recomendación estratégica ni una constatación empírica. En tanto concepto abstracto, está orientado a los fines del conocimiento- es teórico en sentido estricto- y se modifica necesariamente a partir de la mediación de las circunstancias concretas, que configuran a las guerras reales. La interpretación de Aron acerca de esta distinción permite entender el pensamiento de Clausewitz, que es rehabilitado al campo de la teoría política y absuelto de las habituales 
acusaciones, como la de Liddell Hart (Aron, 1987, II: 1-39; Hart, 1933: 119-128).

Aron pudo superar las tergiversaciones de los detractores de Clausewitz pues tenía el dominio de la gran cultura alemana del siglo XIX, en la que el ascenso de lo abstracto a lo concreto y la relación entre Urphänomen y Phänomen, conformaban el medio en el que brotó Vom Kriege como planta solitaria. Por ello es posible plantear que la fuente de los malentendidos es la dificultad de una época positivista para entender un pensamiento surgido en un ambiente romántico.

La cuestión de la relación guerra y política es analizada exhaustivamente por Aron. Clausewitz dice que la guerra es acto político, instrumento de la política, continuación de las relaciones políticas y realización de estas por otros medios.

El concepto de guerra irradia cuatro rayos distintos, que remiten a diversas posibilidades de lo que la política es. De entre ellos, en Paz y Guerra Aron enlaza el de instrumento de la política. «La subordinación de la guerra a la política, como la del instrumento al objetivo, implícita en la fórmula de Clausewitz, fundamenta y justifica la distinción entre la guerra absoluta y las guerras reales» (1963:46).

¿Cómo fundamenta y justifica la idea de la guerra como instrumento a la distinción entre guerra absoluta y guerra real? La introducción de la política como acción racional con arreglo a fines nos orienta hacia un sujeto político, en relación con el cual se instituye el campo de los fines. Ese sujeto, para Clausewitz, es el Estado o el jefe que lo personifica. Su idea de la política depende de la historicidad política occidental, incardinándose en la era de la estatalidad.

¿Por qué hay guerras? En sucesivos pasajes de Paz y Guerra entre las Naciones Aron vuelve sobre la cuestión. Rescata la distinción clausewitziana entre intención hostil y sentimiento hostil, subrayando a la primera como causa de la guerra.

En la Segunda Parte o Sociología despliega la crítica de las teorías dogmáticas basadas en la sobrestimación o absolutización de un aspecto parcial, se trate del espacio, el número o los recursos naturales. La crítica aroniana a la polemología de signo demográficobiologicista, a la geopolítica, a la teoría marxista-leninista del imperialismo, siguen el modelo de la crítica de Clausewitz a la escuela de la guerra de Von Bullow, que elevó a dogma de la acción la maniobra geométrica, predominante en las guerras del primer concierto europeo, anteriores a las campañas napoleónicas.

La intención hostil como causa de la guerra es el punto de partida de una idea de lo político que pivotea en torno a la polaridad amigo- enemigo. La enemistad en sentido clausewitziano no es ética, ni ocasional, sino existencial, ya que la misma «presencia» de uno contradice la existencia del otro. Dos parecen ser las fuentes de la hostilidad: la posición geopolítica y la diferencia 
ideológica. Acerca de cuál es el aspecto principal de la enemistad- si la ideología o la posición-, Aron elude una definición, aunque destaca el carácter irreductible de la imbricación de ambos términos en la circunstancia política, particularmente en la bipolaridad norteamericano-soviética:

Los dos son enemigos -aunque se asemejen- porque la presencia de uno de ellos trae consigo la eliminación del otro (una vez más dejando aparte el caso de los neutrales). Casi no importa saber si los representantes de uno u otro campo hacen la misma cosa (no la hacen); basta con que se persigan unos a otros para que la hostilidad sea inevitable. (1963:640).

La imposibilidad de la formación de una voluntad general que exprese las voluntades particulares de los Estados miembros patentiza la dificultad insalvable de la Organización de las Naciones Unidas: la construcción de una organización internacional en la época de los Estados nacionales, indisolublemente ligados al principio de la soberanía que -en su acepción clásicaimplica decisión independiente sin juez superior a la voluntad de cada unidad política. En la situación de bipolaridad norteamericano-soviética, en cambio, la estatalidad está mediatizada por la lucha revolucionaria mundial, impulsada desde los Estados revolucionarios.

Aron extrema el razonamiento hasta llevarlo al análisis de la hipótesis de construcción de una federación planetaria que deje atrás la era de la estata- lidad, y que organice a la Humanidad entera bajo una única institucionalidad. Incluso en una situación imaginaria de ese tipo -cuyas condiciones de posibilidad son tan difíciles que dependen del azar- postula la continuidad de la lógica de la enemistad. "¿Puede concebirse una sociedad humana sin enemigos?", se pregunta Aron, respondiendo que "no es equivocado decir que el orden político es inseparable de las hostilidades... por debajo de un Estado planetario, los grupos no vivirían en paz si, como las conciencias según Hegel, cada uno quiere la muerte del otro». (1963: 877).

\section{VI}

Si Clausewitz es el teórico fundamental de la guerra y el modo en que lo trabajó en Paz y Guerra le pareció ulteriormente insatisfactorio, se desprende que más deficiente fue, desde esta perspectiva, el tratamiento de Clausewitz en un trabajo anterior como Les guerres en chaîne.

¿En qué consiste esa deficiencia en el tratamiento teórico de Clausewitz en Paz y Guerra entre las Naciones? Aron no lo dice, pero puede encontrarse en las diferencias entre Paz y Guerra entre las Naciones y Pensar la Guerra, Clausewitz.

En Pensar la Guerra, Clausewitz, publicado en 1976, Aron aborda la misma cuestión que en Paz y Guerra entre las Naciones: el problema teórico e histórico de la política y la guerra. 
Por lo tanto, la teoría de las relaciones internacionales aroniana no solo hay que buscarla en Paz y Guerra entre las Naciones sino también en Pensar la Guerra, Clausewitz, ya que ahí encuentra el núcleo teórico político-estratégico clausewitziano un tratamiento plenario, que lleva en sí la reducción de la extensión multidisciplinaria (desplegada en Paz y Guerra) y la profundización de la conceptualización teórico-política.

Una de las diferencias fundamentales en el tratamiento de las relaciones internacionales entre Paz y Guerra y Pensar la Guerra -cuya identidad de objeto aparece reflejada desde el mismo título de ambos libros- es el pasaje de una concepción instrumental de la guerra a una concepción totalizante existencial. En términos de la tradición filosófica alemana- a la que Aron pertenecía- el cambio de modalidad desde Paz y Guerra a Pensar la guerra puede enunciarse como el pasaje del entendimiento (Verstand) -en tanto comprensión analítica ordinaria-, a la razón (Vernunft) en tanto modalidad sintética superior.

En Paz y Guerra, la fuerza del entendimiento aroniano relaciona categorías de disímil procedencia, en la exposición escalonada desde las figuras del diplomático y el soldado, pasando por los distintos tipos de paz y de guerra, hasta el análisis de los diversos sistemas. La unidad teórica de Paz y Guerra amenaza con difuminarse en la construcción de un registro direccionado desde lo múltiple a lo múltiple, desde las categorías ( paz y guerra, estado de naturaleza, relaciones entre unidades políticamente autocentradas, sistemas homogéneos y heterogéneos, etc.) hacia un intento de síntesis que no acaba de construir un concepto de lo político. A fuerza de emplear recursos de diferente procedencia -acaso discordantes-, el estatuto epistemológico de la multidisciplinariedad reproduce la fragmentación en la construcción fallida de la unidad de objeto.

En Pensar la Guerra, la totalidad política-guerra permite constituirse en el centro motor unificante desde el que se avanza en el encuadramiento de la realidad histórica hacia nuevas síntesis conceptuales.

Mientras en Paz y Guerra la paz y la guerra aparecen como sendos roles del diplomático y el soldado, en Pensar la Guerra, esa modalidad instrumentalque remite a la concepción weberiana del político como profesión (Weber, 1997: 1062-1106) y también al conductismo -deja lugar a la distinción entre politics y policy, política como situación y política como línea de acción, respectivamente. La interpretación aroniana de Clausewitz modifica la historia de la recepción de la obra, y nos devuelve la imagen de un pensador radicalmente distinto al que Liddel Hart llamó el «Mahdi de las masas» (1933:119).

La Advertencia de 1827 es el documento histórico en el que Clausewitz plantea la necesidad de revisión de $D e$ la Guerra en función de dos conceptos tardíamente desarrollados, que operan como principios de su pensamiento: 
Pablo A. Anzaldi • Raymond Aron y la teoría de las relaciones internacionales

- La primacía de la política

- Las dos especies de guerra

Aron demuestra que Clausewitz jamás concluyó el tratado ${ }^{4}$. Comenzado en 1816, a partir de la Nota final y la Advertencia de 1827 debía revisarse y modificarse en su conjunto, al punto que solo el capítulo 1 del libro I puede considerarse terminado, lo que nos proporciona una idea de lo que hubiera sido.

Sobre la base de descubrir lo inconcluso del tratado, la revisión bosquejada en la Advertencia de 1827 y la conclusión únicamente del capítulo 1 del Libro I, Aron despliega una interpretación plenaria de Clausewitz.

Aron subraya que Vom Kriege contempla dos especies de guerra: la primera, que concluye en el aniquilamiento y la rendición incondicional de uno de los duelistas; la segunda, que concluye en la observación armada y la paz negociada (1987:107). La segunda especie, incluso, es la más usual. Ambas tienen en común ser igualmente políticas.

\section{VII}

La extraña trinidad es la dimensión interna de todas las guerras. No se trata, pues, de un concepto abstracto destinado a superarse a medida que se avanza en los niveles de concreción. Por el contrario, la trinidad es la esencia

4 Designamos a De la Guerra con ese nombre introducido por Aron. de la guerra entendida como momento estructural de la realidad.

(...) la definición trinitaria aporta, no obstante, una novedad decisiva: sólo ella vale para las guerras reales y ella vale para todas las guerras reales. Aléjense más o menos de la guerra absoluta, las guerras no son menos guerras desde el momento en que nos remitimos a la definición trinitaria, que sirve de fundamento tanto a la teoría como a la historia y la doctrina (1987:88).

El tránsito de una especie a otra, en principio determinado por el cambio en las relaciones entre el fin político y el objetivo militar, transforma permanentemente la apariencia de la guerra. Aron interpreta la proposición de la guerra como camaleón en tanto clave de la historicidad y complejidad de todas las guerras, ya que «la guerra es un camaleón en los dos sentidos del término, la guerra es otra de coyuntura en coyuntura, compleja en cada coyuntura» (1987: 40).

Lo que nos permite enlazar con la trinidad como núcleo de determinación principal o esencia en tanto momento estructural de la realidad (Zubiri, 1985: 97) de la guerra, desde el interior de los sujetos enfrentados.

La extraña trinidad no es un concepto puramente teórico, sino un fenómeno originario que contiene tres momentos constitutivos de la guerra en cuanto tal. Se trata de notas que los sujetos de la guerra poseen efectivamente, imprimiendo el carácter a esta: no son ni pueden ser indiferentes a la teoría porque su organización y gravi- 
tación relativa determina la especie de la guerra.

No nos apartamos de Aron si desdoblamos cada momento de la trinidad en propiedad y sustancia, en el estilo de la metafísica tradicional. En efecto, la confluencia del odio (Hass), la enemistad (Feindschaft) y la violencia primitiva de su esencia (ursprüngliche Gewaltsamkeit) como ciego impulso natural (blinder Naturtrieb) se corresponde con el pueblo (Volk), que representa el estado de naturaleza superado, negado y conservado como negado (Aufebung) por la acción de los dos niveles superiores de la trinidad, sin los cuales la guerra no podría ser «medio serio para un fin serio» $\mathrm{y}$ "continuación de la política con medios violentos». Por el contrario, sería simplemente estado de naturaleza: ausencia de fines y de proporción, mera violencia desencadenada, imposibilidad de distinciones morales y políticas, en suma, inexistencia de política.

El segundo momento está constituido por notas más elevadas: el juego del azar y las probabilidades que remiten al talento y el valor de la actividad libre del alma, correspondiente al jefe militar y su ejército. La diferencia con la escuela de base geométrica se manifiesta en la apreciación de la estrategia de las operaciones militares como un verdadero arte, y del jefe militar como artista. Toda la teoría del genio militar expuesta en el capítulo III del Libro I desarrolla la teoría del genio de origen romántico, que postula la creación artística como fenómeno superior e independiente de las reglas del arte.

El tercer momento, finalmente, es el de instrumento político subordinado que es la guerra y converge en el dominio del entendimiento puro, que corresponde al gobernante político.

La unidad de los tres momentos y la diversa modalidad concreta de articulación en cada caso determinan la especie de guerra:

Ya que todas las guerras reales comportan, aunque en proporciones diferentes, los tres elementos- pasión del pueblo, libre actividad del alma del jefe militar, entendimiento político y dirección de la guerra por el Estado-, ¿por qué no buscar las causas de la guerra que asciende a los extremos, así como las causas de las guerras que descienden hasta la observación armada? (Aron, 1987:107)

La extraña trinidad de la guerra no necesariamente desplaza a la guerra absoluta; más bien posibilita dar cuenta de la particular combinación históricoconcreta que aproxima o aleja a una guerra real del concepto absoluto de guerra, que el afán romántico de infinitud del pensamiento de Clausewitz buscó. «Las guerras que se aproximan a la perfección no son más ni menos políticas que las otras: la política misma determina su carácter absoluto» (1987:91). 
Pablo A. Anzaldi • Raymond Aron y la teoría de las relaciones internacionales

\section{VIII}

Las oscilaciones de Clausewitz son en gran medida clarificadas por Aron. El problema de la totalidad guerra-política es acaso de los más espinosos, ya que pone en juego tanto a uno de los núcleos fuertes de la interpretación aroniana, como al movimiento dialéctico de polaridad clausewitziana.

El pensamiento de Clausewitz oscila entre la interpretación de la guerra y la política como unidad en la complementariedad en función de una teoría de lo político como teoría del Estado en tanto inteligencia del Estado personificado, y la tesis de la política como totalidad diferencial compuesta por la paz y la guerra, en la que esta es determinada por aquella, entendida como orden político.

La interpretación aroniana está orientada en el predominio del pensamiento de Clausewitz hacia esta última concepción, que constituye su novedad radical, así como un principio decisivo de reorientación teórica. Veamos.

Aron denomina fórmula a la conocida frase clausewitziana que define a la guerra en tanto «continuación de la política por otros medios». La fórmula aparece tres veces en el tratado. En primer lugar, como título del punto 24 del capítulo I del Libro I: «la guerra es la mera continuación de la política por otros medios» (Clausewitz, 1960: 24). Luego, en el cuerpo del texto, dice que "la guerra no es simplemente un acto político, sino un verdadero instrumento político, una continuación de la acti- vidad política, una realización de la misma por otros medios» (id.).

La interpretación plenaria y política desarrollada por Aron subraya la importancia de la Advertencia de 1827 y la necesidad de tomar en cuenta esos criterios en la lectura de toda la obra y en el esfuerzo de reconstrucción del proyecto teórico. De ese modo, Aron desprenderá a Clausewitz de las condiciones técnico-militares de la época, que abundan en las partes tácticas y operacionales de Vom Kriege, y lo elevará a un plano específicamente político.

La novedad del pensamiento de Clausewitz no radica en el descubrimiento de la relación guerra y política, que Maquiavelo y los escritores militares anteriores habían destacado. El aporte de Clausewitz se encuentra en el modo radical en que concibe la relación guerra-política, tomando en consideración las dos especies de guerra y la extraña trinidad.

La revisión proyectada buscaba recrear y ensamblar nuevamente el tratado. Al no haberlo completado Clausewitz, el problema de la revisión adquiere un carácter hipotético.

La tercera vez que aparece la fórmula es en el punto B del capítulo 6 del Libro VIII, titulado «la guerra como instrumento de la política» que es el otro capítulo de Vom Kriege, además del capítulo 1 del Libro I, que Clausewitz revisó( aunque en este caso parcialmente). La fórmula es expresada de un modo más profundo y ya asoma la imbricación estructural de la guerra en la política como un todo: 
Habríamos considerado esta unidad desde el principio, si no hubiera sido necesario subrayar estas contradicciones evidentes y considerar también separadamente los diferentes elementos. Esta unidad es la concepción de que la guerra es sólo una parte del intercambio político y, por lo tanto, en ninguna forma constituye una cosa independiente en sí misma (1960:565).

Clausewitz subraya que la guerra es parte de un todo; ese todo es la política. Aron encuentra que la política en Clausewitz tiene dos sentidos: objetivo, politics o situación política; y subjetivo, policy, línea política o plan político del jefe de Estado (inteligencia del Estado personificado). La guerra es parte del intercambio político, es propiamente política. La política, objetiva o subjetiva, es paz y es guerra. Aron lo señala concretamente:

Clausewitz pasa del condicionamiento de la guerra por la política a la idea decisiva de la acción política por las armas, punto de vista superior que funda la unidad del concepto de guerra pese a la diversidad de guerras y la dualidad de las especies. No es la concepción inicial de la guerra absoluta lo que permite subsumir en un solo concepto la diversidad histórica de las guerras sino la naturaleza intrínsecamente política de la acción bélica. Ya el Mariscal de Sajonia evite a menudo la batalla o Napoleón la busque siempre, la guerra sigue siendo guerra porque, en uno y otro caso, los Estados actúan políticamente por la violencia, sean cuales fueren las modalidades de esta última (1987:105).
El condicionamiento representa una relación externa y mecánica de variables, en la que la política aparece como el marco de sentido y como la profesión particular (el diplomático) que funcionalmente impone su directriz a otra profesión particular (el soldado). Tal es lo que ocurre en Paz y Guerra entre las naciones, donde la política es concebida como actividad pacífica de la diplomacia y la guerra como actividad violenta del soldado. La dialéctica de las profesiones subyacente remite a un vínculo externo, no a una totalidad orgánica.

De Paz y Guerra a Pensar la Guerra manifiesta el tránsito desde una relación mecanicista, en la que los miembros vinculados en las extremidades accionan y reaccionan desde una función inalterable (el diplomático como agente de negociación; el soldado como agente de guerra) a una dialéctica concreta, en la que la paz y la guerra son manifestaciones de una misma totalidad orgánico- estructural, la política:

Ya no se trata de oponer las guerras donde interviene mucho la política a aquéllas que no parecen politizadas. Se trata de reconocer dos proposiciones fundamentales: las guerras moderadas a la manera dieciochesca o las guerras de estilo napoleónico son igualmente políticas; unas y otras expresan, en su diversidad, la diversidad del comercio entre los Estados según las épocas. Las guerras a muerte, de estilo napoleónico, parecen pura guerra, mientras que las del Rococó son ante todo políticas. Pero unas no son menos políticas que otras (Aron, 1987:333). 
Pablo A. AnZaldi • Raymond Aron y la teoría de las relaciones internacionales

Acaso la fuente de los malentendidos es el planteamiento mismo de la relación guerra y política, lo que supone virtualmente tanto la diferencia entre ambas como la identificación de la política con la diplomacia y de esta con la paz como imperativo categórico.

A diferencia de Paz y Guerra entre las Naciones, en Pensar la Guerra, Clausewitz, la política y la guerra no son las respectivas conductas de $d i$ plomáticos y soldados. La guerra y la paz son dos modalidades propiamente políticas. Por ello en lugar de totalidad guerra- política sería más ajustado al concepto articularlo como totalidad política: paz-guerra.

El esfuerzo aroniano en la identificación del acto diplomático y el acto militar como momentos estructurales de lo político deja atrás la concepción de lo político como consecuencia de la relación entre el soldado y el diplomático. Cuando en Paz y Guerra entre las Naciones Aron concibe a la política como una función de las variables del diplomático y el soldado, el movimiento del entendimiento se dirige de lo múltiple a lo uno: desde el diplomático y el soldado a la política. El método está orientado desde las partes hacia una síntesis. En cambio, en Pensar la Guerra Aron invierte radicalmente la perspectiva y sitúa el punto de partida en la totalidad política para- desde ahímostrar el despliegue de la guerra como una de sus virtualidades.

Este descubrimiento aroniano está decisivamente determinado por Clausewitz, quien decía que «en su punto de vista más elevado, el arte de la guerra se transforma en política, pero, por supuesto, en una política que libra batallas en lugar de escribir notas diplomáticas»( Clausewitz, 1960: 568). Punto de vista más elevado, el de la totalidad, que Aron repite casi textualmente al afirmar que «la política se vale de cañones o de notas; recurre a la violencia tanto como a la palabra» (1987:333).

La diferencia entre la síntesis compositiva de partes y el despliegue de virtualidades de una totalidad-que marca el pasaje de Paz y Guerra a Pensar la Guerra- es el giro del pensamiento aroniano.

En la perspectiva de la totalidad en Pensar la Guerra, Clausewitz determina que la política tiene una prioridad ontológica y formal sobre la función del diplomático y del soldado. De este modo, la paz y la guerra son situaciones distintas que constituyen dos momentos de una única totalidad política.

Si la guerra es parte de la totalidad política, el jefe político-estatal es la inteligencia del Estado personificado: asume el conocimiento de la totalidad política, de la paz y la guerra. El jefe militar también es político, pero concentra su actividad en una parte de la política, la que intercambia disparos. Como la parte al todo, este se subordina a aquel. La distinción de niveles de realidad de la totalidad política-guerra permite a Clausewitz ordenar las definiciones pertinentes: la política es la inteligencia del Estado personificado, la estrategia es la combinación y explotación del resultado de las batallas, y la táctica es 
la conducción de la fuerza militar en la batalla.

En caso de estar reunidas las capacidades diplomáticas y las militares en una única persona, o aun en el caso que el jefe militar conduzca el conjunto lo hará siempre- objetivamente- en función política. Podrá tratarse de una política "militarista», "belicista» o lo que fuere, pero siempre será política, ya que estará presidida por fines políticos.

De la tesis de la primacía de la política y la extraña trinidad, en tanto notas constitutivas de la totalidad política, se desprende tanto una reorientación analítica de la política internacional, como una aproximación a un concepto de lo político fuertemente influenciado por Carl Schmitt.

La naturaleza de lo concreto es universalmente dinámica. El pensamiento dialéctico de Clausewitz se anuda con la constatación de la "guerra como camaleón»: sigue siendo tal, pero cambia de color. Es la metamorfosis de la guerra, que el pensamiento clausewitziano busca reflejar. No es un movimiento caótico sino estructuralmente determinado por la primacía de uno u otro de los componentes de la trinidad, así como por las características particulares que asumen los mismos.

La parte recapitula al todo, la teoría clausewitziana es orgánica, aunque la redacción definitiva de la obra jamás haya sido realizada, quedando para la posteridad la tarea de interpretarla y recrearla tomando en consideración la primacía de la política y las dos especies de guerra. La vigencia de Clausewitz está sujeta a la investigación de la historicidad de la guerra, de su metamorfosis en función de las realidades políticas y de las totalidades histórico-concretas.

\section{IX}

Aron asume una idea de la política como inteligencia del Estado personificado. Sin embargo, nos parece posible establecer que lo que sea esa inteligencia del Estado personificado y su modalidad de concreción en la situación política o politics, se apoya en un supuesto de lo político como relación amigo- enemigo, originariamente develado por Carl Schmitt:

La específica distinción política a la cual es posible referir las acciones y los motivos políticos es la distinción de amigo (Freund) y enemigo (Freind). Ella ofrece una definición conceptual, es decir un criterio, no una definición exhaustiva o una explicación del contenido. En la medida en que no es derivable de otros criterios, ella corresponde, para la política, a los criterios relativamente autónomos de las otras contraposiciones: bueno y malo para la moral, bello y feo para la estética y así sucesivamente. En todo caso es autónoma, no en el sentido de que constituye un nuevo sector concreto particular, sino en el sentido de que no está fundada ni sobre una ni sobre algunas de las otras antítesis, ni es reductible a ellas (1986:23).

La definición de lo político desde la enemistad permite construir una teoría de lo político no subordinada a una teoría del Estado. Cuando Aron se pregun- 
ta qué ocurriría en caso de establecerse un gobierno o Estado mundial anticipa, en el plano hipotético, la continuidad de la conflictividad como manifestación de la realidad de lo político, en oposición al ideal kantiano de la paz perpetua y a la idea de imperio.

La distinción schmittiana amigoenemigo es, en un sentido, un presupuesto del pensamiento aroniano; en otro sentido, es la patentización de un estrato más profundo de la realidad política.

En Paz y Guerra entre las Naciones Aron decía que "el orden político es inseparable de las hostilidades" (1963:877). Por ello la distinción schmittiana amigo-enemigo no sólo es un presupuesto teórico, sino también, es un momento estructural de la realidad política. En otros términos, la relación amigo-enemigo es una distinción teórica correspondiente a una polaridad existencial.

Las notas de lo político, la paz y la guerra, aparecen como momentos reunidos en el interior de la realidad política. Cuando Aron aborda la posibilidad de un Estado mundial y proyecta la continuidad de la hostilidad, sostiene una teoría de lo político que no se confunde con la estatalidad sino en lo que esta tiene de etapa histórica. Aron no desconoce la realidad de los Estados nacionales ni la gravitación de la misma en las relaciones internacionales y en su propia teoría política. Pero esto no lo asimila sin más con el realismo, ya que para Aron la estatalidad no es un principio sino un momento histórico, una realidad concreta e históricamente acaecida.

Deliberada o no, una teoría de lo político de ese tipo es tributaria de la tesis schmittiana que afirma que «el concepto de Estado presupone el de político» (1986:15) y no a la inversa.

En este sentido, el hilo conductor del pensamiento aroniano es la idea de lo político como hostilidad en tanto momento estructural de la realidad política.

Para aclarar la cuestión, en términos filosóficos, comparece en nuestra investigación la distinción zubiriana entre sustantividad y sustancia (Zubiri, 1985), que posibilita la liberación del pensamiento de la hipóstasis de la sustancia y, en consecuencia, de la determinación historicista. El pensamiento aroniano adquiere, de este modo, la más plenaria independencia del historicismo y, lo que es lo mismo, la más plenaria condición científica. Veamos:

Sustantividad no es sustancialidad. La sustantividad, en efecto, tiene el carácter formal de sistema de notas y no de sujeto de ellas. Es un carácter de la unidad de las notas entre sí, pero no es un sujeto oculto tras ellas. No es la perseidad de la sustancia, sino la suficiencia en el orden del sistema. Por tanto, la esencia como momento de la sustantividad es momento de un sistema y no determinación de un sujeto (Zubiri, 1985:343).

La esencia de las relaciones internacionales está estructuralmente determinada por la esencia de lo político. Es sustantividad, esto es, reunión de notas 
y no sujeto de ellas. El sujeto es la sustancia. Por ello decimos que la esencia de lo político, es decir, de las relaciones internacionales, es la enemistad como momento que reúne en sí las notas de paz y guerra. La estatalidad, en cambio, es la sustancia o sujeto de predicación, que lleva en sí la determinación de su transformación y adquiere, entonces, mutabilidad y acaso contingencia.

En contraposición a la objeción más extendida, un pensamiento político que reúna desde la distinción amigo- enemigo las notas de paz y guerra como momentos estructurales de la sustantividad de lo político, no implica una ética belicista. Por el contrario, tanto en Schmitt como en Aron, la enemistad no es intencional sino existencial.

El enemigo es simplemente el otro, el extranjero (der Frende) y basta a su esencia que sea existencialmente, en un sentido particularmente intensivo, algo otro o extranjero...decidir si la alteridad del extranjero en el conflicto concretamente existente significa la negación del modo propio de existencia y si es por ello necesario defenderse y combatir, para preservar el propio, peculiar, modo de vida.( Schmitt, 1985:23)

La guerra y la paz son absorbidas e integradas a una concepción de lo político definida por Carl Schmitt y conceptualmente preparada, de manera decisiva, por Clausewitz. En ese punto en el cual el pensamiento de Aron se entremezcla con el de Clausewitz, en el que la esencia de lo político como sustantividad es un momento estructural configurado por las notas de paz y guerra, que atraviesa las diversas manifestaciones sustanciales e históricas, Aron forma parte de una tradición teórica en la que Schmitt es un destacado antecedente, en tanto Clausewitz hace las veces de padre fundador. La comunidad de pensamiento de Clausewitz, Schmitt y Aron es ostensible:

La identidad de naturaleza entre el acto bélico y el acto político plantea dos proposiciones mayores: la políticaobjeto determina la guerra y los caracteres que ella presenta; la política- sujeto la conduce con miras a los fines que sugiere o impone la política- objeto; el instrumento militar, como cualquier otro instrumento, debe ser manipulado de acuerdo con su naturaleza y sus leyes, pero el instrumento se somete a la voluntad de quien lo manipula. El acto de fuerza sigue siendo intrínsecamente un acto político, un elemento de la dialéctica de las voluntades enfrentadas (Aron, 1987:178).

\section{$\mathrm{X}$}

En esta investigación hemos trazado tres cortes - apoyados en los respectivos textos- en los que pueden reconstruirse sucesivamente tres momentos del pensamiento aroniano en relaciones internacionales. Los conceptos de política, guerra y técnica han sido de especial relevancia para demostrar las diferencias y reorientaciones en los tres momentos.

El encuentro y la profundización en el pensamiento clausewitziano posibilita la construcción de la teoría 
política en la que la totalidad política paz y guerra, es decir, la repetición de lo mismo, despliega la diferencia. Es el momento culminante del pensamiento aroniano.

La investigación en los tres cortes realizados al pensamiento aroniano muestra como el concepto de lo político ha ido creciendo, hasta absorber en la totalidad política los momentos técnico y bélico. Desde la primera fase a la última, lo político ha pasado desde una condición arrastrada por la dinámica de la guerra total, determinada por la movilización técnica del mundo, hasta reunir en la vértebra de la enemistad las distintas variaciones de las notas paz y guerra.

La extraña trinidad posibilita una morfología de lo político-militar que se expresa diversamente con arreglo a variaciones empíricas, de la primera a la segunda especie de guerra, recapitulando la razón (Vernunft) goethiana que imbrica morfología y metamorfosis (Goethe, 2002:83).

El pensamiento aroniano -en la más plenaria imbricación con el clausewitziano- nos patentiza irremediablemente el sino de lo político en la paz y la guerra. Esa unidad de notas está sostenida por una distinción última: la de amigo-enemigo. Cuando la esfera sustantiva de la distinción amigo-enemigo adquiere sustancia (social, interestatal, intraestatal, religiosa, cultural, ideológica, etc.) estamos ante la realidad de lo político. La confusión entre el momento sustancial de los asuntos públicos con lo político, emana de la hipóstasis de los
Estados nacionales. En la Edad Media, la política pasaba por otros órdenes concretos y un pensamiento como el aristotélico podía ser leído en clave eclesiástica o imperial, o propiamente metafísica, quedando extraviada su circunstancia histórica.

La proyección de la conflictividad política ante la eventualidad improbable del establecimiento de un gobierno mundial se sostiene sobre lo político como relación amigo-enemigo. La concepción aroniana de las Naciones Unidas como campo de conflicto muestra la emergencia de la enemistad política y la imposibilidad de la normatividad jurídica. En ese aspecto, la distinción ontológico-política entre naturaleza y convención, y su derivado, la alternativa política entre inclinación y deber o, si se quiere, entre la verdad efectiva de la cosa según Maquiavelo y el imperativo categórico kantiano, ubican a Aron más bien en los primeros términos de las opciones.

Por otra parte, en el plano de la variación fenomenológica, el pensamiento aroniano libera el concepto de lo político de su adscripción a la sustancia del Estado. Acaso Aron no lo haya desarrollado con la claridad y profundidad schmittiana, y su anclaje en Clausewitz y su concepto de la guerra como fenómeno interestatal, en tensión con la metamorfosis de la guerra expresada en la figura del camaleón, muestran que la teoría política no siempre vuelve sobre sus pasos para dar cuenta de su fundamento y desarrollo. 


\section{BibLIOGRAFÍA}

Aron, Raymond, (1973), Un siglo de guerra total, Buenos Aires, Editorial Rioplatense.

, (1962), Paix et guerre entre les nations, París, Calmann- Lévy.

, (1963), edición en español Paz y guerra entre las Naciones, Revista de Occidente, Madrid, traducción de Luis Cuervo. , (1976), Penser le guerre. Clausewitz, París, Gallimard (1987), Edición en español Pensar la guerra. Clausewitz, Buenos Aires, Instituto de Publicaciones Navales.

, (1983), Memoires. 50 ans de reflexion politique,París, Julliard; edición en español.

(1985), Memorias, Madrid, Alianza Editorial.

, (1981), Le Spectateur engagé. Entretiens avec Jean-Louis Missika et Dominique Wolton,París, Julliard, edición en español (1983), El Observador comprometido, Buenos Aires, Emecé.

Clausewitz, Carl(1960), De la Guerra, Buenos Aires, Mar Océano, traducción al español de RW de Setaro.
Del Arenal, Celestino (1994), Introducción a las Relaciones Internacionales, Madrid, Tecnos, pp. 166-179.

Dougherty, James E. y Pfaltzgraff(1993), Teorías en pugna en las Relaciones Internacionales, Buenos Aires, Grupo Editor Latinoamericano, Colección Estudios Internacionales, pp.126-130.

Hart, Liddel (1933), The Ghost of Napoleon, Londres, Faber and Faber.

Hoffmann, Stanley (1991), Jano y Minerva. Ensayos sobre la guerra y la paz, Buenos Aires, Grupo Editor Latinoamericano, pp.63-78.

Goethe, Johann Wolfgang von, (2002), Goethe y la ciencia, Madrid, Biblioteca de Ensayo, ediciones Siruela.

Schmitt, Carl (1985), El concepto de lo politico, México, Folios Edición, pp.15-76.

Spengler, Oswald, (1993), La decadencia de Occidente, Madrid, Planeta-Agostini.

Weber, Max ( 1997), Economía y Sociedad, México, Fondo de Cultura Económica, pp.1062-1106.

Zubiri, Xavier (1985), Sobre la esencia, Madrid, Alianza Editorial- Sociedad de Estudios y Publicaciones. 